\title{
DESAFIOS CONTEMPORÂNEOS EM PROL DA LIBERDADE
} RELIGIOSA

\author{
Ivanir dos Santos ${ }^{1}$
}

\begin{abstract}
Resumo: A intolerância religiosa, assim como o racismo, ainda é um dos grandes desafios que nos impede de construir e promover uma sociedade mais justa e mais igualitária. Ao debruçarmos sobre as construções históricas do Estado brasileiro, facilmente nos é perceptível compreender que as lutas cotidianas pela liberdade de culto e pela tolerância passaram a ser constante e sempre presente na vida dos adeptos das religiôes de matrizes africanas, principalmente, entre os século XX e XXI. Lutas essas que também passaram a guiar os movimentos de promoção do diálogo inter-religioso, direitos humanos e pela equidade religiosa. Destarte, o presente texto tem por objetivo fazer uma brevíssima análise comentada sobre os desafios contemporâneos em prol da construção da liberdade religiosa na sociedade brasileira à luz do artigo escrito pela professora doutora Ana Paula Mendes de Miranda.
\end{abstract}

Palavras-Chaves: liberdade religiosa; tolerância; diálogo inter-religioso.

\begin{abstract}
Religious intolerance, like racism, is still one of the great challenges that prevent us from building and promoting a more just and egalitarian society. When poring over the historical constructions of the Brazilian State, it is easy to understand that the daily struggles for freedom of worship and tolerance have become constant and always present in the lives of followers of African-based religions, especially between the 20 th and 20 th centuries. XXI. These struggles also began to guide movements to promote interreligious dialogue, human rights and

1 Doutor em História Comparada, professor e orientador no Programa de Pós-graduação em História Comparada da Universidade Federal do Rio de Janeiro, coordenador da Coordenadoria de Religiōes Tradicionais Africanas, Afro-brasileiras, Racismo e Intolerância Religiosa (ERARIR/LHER/UFRJ) e Interlocutor da Comissão de Combate à Intolerância Religiosa (CCIR), Brasil. E-mail: ivanirdossantos.academia@gmail.com. ORCID: https://orcid.org/0000-0001-6614-3184.
\end{abstract}


religious equity. Thus, this text intends to make a very brief commented analysis on the contemporary challenges in favor of the construction of religious freedom in Brazilian society in the light of the article by professor Ana Paula Miranda.

Keywords: religious freedom; tolerance; interfaith dialogue.

Como bem é possível analisar ao nos debruçarmos sobre os contextos de forjamento da sociedade brasileira, o preconceito, a discriminação e a intolerância religiosa sempre foram, e continuam sendo, um fator recorrente na história das religióes desde o período colonial, quando aqui aportaram os primeiros homens negros africanos e mulheres negras africanas na condição de escravos, com suas culturas e religiosidades. Assim sendo, na condição de escravos a possibilidade dos africanos e africanas, bem como seus descendentes, de exercerem suas "religiosidades" 2 e práticas culturais durante boa parte da história do Brasil, foi por meio das "práticas sincréticas", uma ação velada que tinha por fim ocultar a exaltação de seus pertencimentos ancestrais religiosos que suas tradiçóes, culturas e religiosidades sobreviveram. Cabe compreender as mobilizaçôes e as lutas de grupos religiosos de matrizes africanas contra todas as tentativas de supressão de seus direitos a partir de suas experiências como açôes significativas e resultantes de seus acúmulos históricos de resistência a todas as formas de perseguiçôes.

Deste modo, Ana Paula Miranda busca refletir sobre as estratégias de mobilização política dos terreiros de religiôes de matrizes africanas em resposta às políticas "cristofascistas" que vêm se disseminando e crescendo na sociedade brasileira. Para tal, a referida autora aponta em suas análises, voltadas para a compreensão das mobilizaçôes dos "afrorreligiosos" que solidificaram tais mobilizaçôes e são hoje um dos pontos de fortalecimento das resistências cotidianas contra todas as formas de opressóes religiosas.

Iniciando suas análises em 2008, Miranda nos permite rememorar as experiências de mobilização e organização da Comissão de Combate à Intolerância

2 Aqui entendida através de práticas espirituais, culturais e sociais.

3 Termo adotado pela autora para nomear os adeptos das religióes de matrizes africanas.

Debates do NER, Porto Alegre, Ano 2 I, N. 40, P. 203-2 Io, Ago./DEZ. 202 I 
Religiosa (CCIR) e da Caminhada em Defesa da Liberdade Religiosa como açóes válidas e expressivas ao que tange à defesa e garantia dos direitos.

O CCIR é um fórum composto por religiosos e religiosas de várias denominaçôes e crenças que tem o intuito de promover a liberdade religiosa e a luta contra a intolerância religiosa em suas mais diversas modalidades no Brasil. O advento da organização se deu após o fatídico episódio ocorrido em uma comunidade da Ilha do Governador, em que pessoas adeptas da umbanda e do candomblé foram expulsas de seus lugares de culto por lideranças locais ligadas ao crime organizado, além de terem os seus barracóes queimados, imagens quebradas e sofrerem ameaças de morte, já que esses religiosos não quiseram se converter.

O caso foi veiculado pelo o jornal Extra, através das matérias da sua série jornalística "O tráfico remove até a fé", em que foram denunciadas as diversas arbitrariedades cometidas contra adeptos religiosos de matriz africana, expulsos pelo traficante Fernandinho Guarabu, no Morro do Dendê. A matéria foi apenas uma das inúmeras denúncias dos casos de intolerância religiosa no Brasil, porém, a novidade que se expressava era a infortunada união entre a religião e o tráfico em prol de uma limpeza étnico-religiosa, em que o alvo que estava na mira do tiro da intolerância era o conjunto das religióes e religiosidades de matrizes africanas. Miranda aponta em seu texto que, com a mudança de foco nas conversôes de criminosos e traficantes, surge um novo ator denominado "traficante evangélico" que passa a agir com truculência contra os terreiros, por meio de ataques violentos e táticas de difusão do medo.

Ainda em 2008, mesmo sob açôes de violência e tentativas de privações de liberdades religiosa e de culto, em resposta a tal arbitrariedade, religiosos e religiosas de matrizes africanas buscaram chamar a atenção das autoridades da cidade do Rio de Janeiro através de um ato público em frente à Assembleia Legislativa do Estado do Rio de Janeiro (ALERJ). Compreendendo que a intolerância religiosa, assim como o racismo, são frutos das formas de sistematização e hierarquização herdadas pela sociedade brasileira ao longo dos séculos, os membros e integrantes da CCIR vêm buscando, ao longo dos seus 14 anos de existência, construir e fomentar sobre três eixos: i) a realização 
de Fóruns de Diálogo Inter-religioso, a fim de promover debates, análises e conscientização sobre a importância da liberdade religiosa em um Estado laico; ii) a realização da Caminhada em Defesa da Liberdade Religiosa ${ }^{4}$, que acontece anualmente no terceiro domingo do mês de setembro na Orla de Copacabana, na cidade do Rio de Janeiro, com abrangência e articulaçáo nacional; iii) a conscientização da importância da implementaçáo da proposta do Plano Nacional de Combate à Intolerância Religiosa, entregue ao então presidente Luiz Inácio Lula da Silva, no dia 20 de novembro 2008.

Tais açôes de resistência corroboram com a argumentaçáo de Miranda, quando a mesma discute sobre o protagonismo dos adeptos das religióes de matrizes africanas para defender o reconhecimento de seus direitos na esfera pública como estratégia da "política dos terreiros". Vale ressaltar que boa parte dos governantes brasileiros, em suas múltiplas esferas e lados, náo demonstram "simpatia" ou envoltura para a construção de açóes concretas que possam propiciar políticas públicas voltadas para tais açôes de protagonismos. Basta aqui mencionar que o Plano Nacional de Combate à Intolerância, de 2008 , até o presente momento ainda não foi implementado e nem teve seus elaboradores convidados para pensar e projetar a sua viabilidade.

Outrossim, podemos apontar que tal descaso e descompromisso com o "povo de santo"s, além de ser recorrente, é fruto da imbricação entre o racismo e a intolerância religiosa. Sim, pois compreendo que o racismo e a intolerância religiosa estấo de mãos dadas e compóem, estruturam e hierarquizam as relaçóes sociais no Brasil. No entanto, dialogando com o debate proposto por Ana Paula Miranda, ao que tange analisar os casos de violências religiosas como intolerância religiosa ou racismo religioso, quero aqui fazer algumas observaçôes utilizando, também, como ponto de diálogo a escritora Grada Kilomba.

4 Para conhecer minhas análises sobre o evento, indico a leitura do meu livro "Marchar não é caminhar: interfaces políticas e sociais das religióes de matrizes africanas no Rio de Janeiro", publicado em 2019.

5 Termo que também é comumente utilizado por religiosos e religiosas de matrizes africanas para referenciar os grupos religiosos que se dedicam aos cultos aos orixás no Brasil.

Debates do NER, Porto Alegre, Ano 2 I, N. 40, P. 203-2 Io, Ago./DeZ. 202 I 
Kilomba (2020, p. 13) afirma que "só quando se reconfiguram as estruturas de poder é que as muitas identidades marginalizadas podem também, finalmente, reconfigurar a noção de conhecimento". Adotando essa ideia como um ponto focal para a compreensão do racismo e da intolerância religiosa no Brasil, endosso-a destacando que, além de ajustar as estruturas sociais, políticas e econômicas, também precisamos reconfigurar as pessoas que as gerem. Pois são nesses e através desses meios que o racismo e a intolerância religiosa se fortalecem.

Não podemos perder de vista que falar e escrever sobre estes últimos é assinalar os processos de glorificaçáo de um passado escravista e a negaçáo das realidades de violência cotidiana sobre as populaçôes negras e os adeptos das religióes de matrizes africanas. Como bem sabemos, a sociedade brasileira ainda vive sob a exaltaçáo de um passado colonial e, ainda hoje, usa todas as estratégias possíveis para continuar a endossar o processo de marginalizaçáo, invisibilização e estigmatização dos corpos, das culturas e das tradiçóes negras.

Ao meu ver, intolerância religiosa e racismo são açôes criminosas diferentes e, por mais que tenham as mesmas raízes, elas precisam ser compreendidas em suas fundamentaçóes. Por trás das açóes de intolerância como de racismo estão em seu centro a ideia de superioridade versus inferioridade e as construçôes sobre a identidade do outro. Entretanto, Grada Kilomba (2020) mostra que no racismo estão presentes três características: a construção da diferença e valores hierárquicos, que juntos formam o terceiro ponto que é o preconceito. A autora portuguesa ainda pontua que ambos os processos estão intimamente ligados e acompanhados pelo poder histórico, poder político, poder social e poder econômico: "E, nesse sentido, o racismo é a supremacia branca” (Kilomba, 2020, p. 76).

Grada Kilomba ainda argumenta que, dentro da estruturação da supremacia branca, outros grupos raciais náo podem ser racistas nem performar $\mathrm{o}$ racismo, pois não possuem poder: "O racismo, por sua vez, inclui a dimensão do poder e é revelado através de diferenças globais na partilha e no acesso a recursos valorizados, tais como representação política, açôes políticas, mídias, emprego, educação, habitação, saúde" (Kilomba, 2020, p. 76). E diferente 
do que possa permear o imaginário social brasileiro, não podemos dizer que todos os adeptos das religiōes de matrizes africanas são da população negra. Portanto, ao entendermos "racismo religioso", aqui racismo tal como é identificado no Brasil, com base na cor da pele, estamos definindo que existe uma identidade religiosa ligada à cor da pele das pessoas e, ao fazer tal identificação, estamos, possivelmente, "limando" a possibilidade de escolha e criando um condicionamento religioso com base na cor da pele.

Do mesmo modo, náo podemos deixar de refletir que, por muito tempo, as práticas dos homens e mulheres negros eram vistas e tidas como "religiōes negras". Entretanto, essa identificação estava relacionada à identidade que o outro, cristão (branco) colonizador, atribuía às práticas religiosas diferentes de suas crenças e liturgias. Não obstante, tal identificação não eximia, como não exime, a participação e iniciação religiosa de pessoas não negras às religiôes de matrizes africanas.

Daí então, como já salientei em outros artigos, compreendo que "racismo religioso" não tem uma estabilidade ontológica de interpretaçôes sobre os casos de agressões físicas, psicológicas e patrimoniais motivadas pelo ódio religioso. De fato, é óbvio que a intolerância religiosa contra adeptos das matrizes africanas está intimamente ligada ao racismo científico, que ainda perdura no imaginário social coletivo brasileiro. Se compreendemos que pessoas não negras não sofrem racismo, obviamente não podemos dizer que sofrem racismo religioso ao assumir tais identidades culturais e religiosas. Porém, nos debates sobre as questóes raciais no Brasil, o racismo não pode ser apenas o único vetor de identificação dos casos de ódio religioso.

E ainda sou tentado a analisar e dizer que a intolerância religiosa contra as religióes de matrizes africanas tem a ver com a cultura que ela representa e que está ligada às “africanidades" que nos apresentam uma identidade religiosa destoante da religiosidade vigente, a cristã. Uma relação construída com base nas diferenças. Portanto, no Brasil, ao analisarmos as açôes de ódio religioso pelo viés da ideia do racismo religioso, precisaríamos conectar tais análises da ideia de racismo à cultura. 
Bem assim, finalizando meus apontamentos cotejados com o texto de Ana Paula Miranda, vislumbro uma grande inspiração para leitores e um mergulho profundo acerca dos debates, análises e reflexôes propostos pela autora sobre movimentos de mobilizaçôes nacionais e regionais em prol da garantia dos direitos religiosos e as suas definiçôes epistemológicas.

\section{REFERÊNCIAS}

MIRANDA, Ana Paula Mendes de. A “política dos terreiros” contra o racismo religioso e as políticas "cristofascistas". Debates do NER, Porto Alegre, ano 21, n. 40, 2021.

KILOMBA, Grada. Memórias da Plantação: Episódios de Racismo Cotidiano. Tradução: Jessi Oliveira. Rio de Janeiro: Cobogó, 2020.

SANTOS, Carlos Alberto Ivanir dos. Marchar não é Caminhar: Interfaces políticas e sociais das religióes de matrizes africanas no Rio de Janeiro. Rio de Janeiro: Pallas, 2019.

Recebido em: 15/07/2021

Aprovado em: 15/07/2021 


\section{RESPOSTA AOS COMENTÁRIOS}

